\title{
FATTY ACID, AMINO ACID AND VITAMIN COMPOSITION OF INDIAN CATFISH, MAGUR (Clarias batrachus) AND SINGHI (Heteropneustes fossilis)
}

\author{
B. N. Paul ${ }^{1}$, S. Chanda ${ }^{1}$, N. Sridhar ${ }^{2}$, G. S. Saha ${ }^{3}$ and S. S. Giri ${ }^{3}$ \\ ${ }^{1}$ Regional Research Centre of ICAR-CIFA, Kolkata-700 118, West Bengal, India \\ ${ }^{2}$ Regional Research Centre of ICAR-CIFA, Bangalore-560 089, Karnataka, India \\ ${ }^{3}$ ICAR-Central Institute of Freshwater Aquaculture, Bhubaneswar-751 002, Odisha, India
}

\begin{abstract}
The fatty acid, amino acid and fat soluble vitamin content of magur (Clarias batrachus) and singhi (Heteropneustes fossilis) were assayed from collected samples from different geographical locations. Length and weight of collected samples were $(50-235 \mathrm{~g}$ and $165-300 \mathrm{~mm})$ for magur and (50-210g and $190-255 \mathrm{~mm})$ for singhi. The essential amino acid (EAA) and the non-essential amino acid (NEAA) content in magur and singhi did not differ significantly. The Vitamin $A$ and $D$ contents were significantly $(P<0.05)$ higher in magur when compared to singhi. The Vitamin $\mathrm{K}$ content was significantly $(P<0.05)$ higher in singhi compared to magur. Monounsaturated fatty acid (MUFA) content was $38.34 \pm 4.62$ and $49.69 \pm 7.82$ in magur and singhi respectively. Among the MUFA, oleic acid was significantly $(P<0.05)$ higher in singhi. Palmitic acid was significantly $(P<0.05)$ higher in magur than singhi. The PUFA content were $25.52 \pm 1.40$ and $13.86 \pm 0.64$ in magur and singhi respectively. The eicosapentanoic acid (EPA) and docosahexaenoic acid (DHA) content were $2.98 \pm 1.00$ and $3.60 \pm 1.11 ; 2.25 \pm 0.86$ and $1.60 \pm 1.09$ respectively in magur and singhi. The $\omega 3: \omega 6$ ratio in magur was $0.45: 1$ and in singhi $0.82: 1$. Both the catfishes were found to be nutrient rich with amino acid, fatty acid and vitamin.
\end{abstract}

Keywords: Clarias batrachus, Heteropneustes fossilis, vitamins, amino acid profile and fatty acid profile

\section{INTRODUCTION}

Fish is an excellent food for human beings for centuries and is preferred as a perfect diet not only due to its taste and quick digestibility rate but also because of having higher proportions of essential amino acids, vitamins and essential fatty acids for the formation of functional and structural proteins (Kumar, 1992). The nutritional

\footnotetext{
* Corresponding author email: bnpaulcifa@gmail.com
} 
contribution of protein in food depends on its rate of digestibility and ability to provide all the essential amino acid (EAA). The high nutritional value of fish is mainly related to their readily digested proteins which are excellent source of EAA (Sanchez-Alonso et al., 2007). In fish $75 \%$ is moisture and moisture free flesh contains fat, ash and protein. Its constituent amino acids (AA) are used by human for synthesis of proteins (Limin et al., 2006).

Fish is a good source of polyunsaturated fatty acids (PUFAs), viz., the $\omega-3$ and ( -6 PUFAs, which are well known for beneficial effect to human health (Giri et al., 2010, 2011 and Paul et al., 2015). The n-3 PUFAs, especially the eicosapentaenoic acid (EPA and docosahexaenoic acid (DHA) are found in high concentrations in the phosphoglycerides of cellular membranes, and DHA is particularly abundant in the retina and brain, where it has a crucial role in maintaining the structure and function of the excitable membranes of these tissues (Lauritzen et al., 2001 and Mohanty et al., 2016). Arachidonic acid (AA), a PUFA of the n-6 series, is a precursor of biologically important products, such as epoxides, AA-ethanolamide, anandamide and iso-prostanes, an isomer of prostaglandins (Galli and Marangoni, 1997).

The vitamin content in fish muscle varies with species, age, season, sexual maturity and geographical areas. Fat-soluble vitamins act as essential nutrients in important biological processes in the human body. Vitamin A, also called retinol, which controls photoreception and regulates gene expression etc. Vitamin $\mathrm{D}_{3}$ (cholecalciferol) promotes and enhances the absorption and metabolism of calcium and phosphorus in our body. $\alpha$-Tocopherol is the vitamin $\mathrm{E}$ compound with the highest biological activity, which acts as an antioxidant, protecting membrane structures, essential fatty acids, and vitamin A from oxidation (Sau et al., 2004 and Paul et al., 2005).

Keeping in view of the importance of eating fish as health food; the nutrient profile of two Indian catfish viz., magur and singhi has been studied to document the information of amino acid, some vitamins and along with fatty acid profile. The nutrient profile of this fish would provide a guideline for dieticians, medical practitioners and nutritionist in prescribing diet chart for the human population.

\section{MATERIALS AND METHODS}

\section{Collection of Samples}

The fish samples of magur and singhi were collected from different states of India viz., West Bengal, Odisha, Chhattisgarh, Tripura and Andhra Pradesh. Length and weight of Magur collected samples were 50-235g and 165-300 mm and Singhi $50-210 \mathrm{~g}$ and $190-255 \mathrm{~mm}$. The sampling procedure and sample preparation for analysis was followed as per Sankar et al. (2010). 


\section{Amino Acid Analysis}

The amino acid analysis was done as per the method of Ishida et al. (1981). For amino-acid analysis Phenylisothiocyanate (PITC) is used for pre-column derivatization, while reverse phase gradient elution high-performance liquid chromatography (HPLC) separates the Phenylisothiocyanate (PTC) derivatives which were detected by their UV absorbance as Pico Tag method of Waters Associates.

\section{Vitamin analysis}

The fat soluble vitamins Retinol (Vitamin A), Cholecalciferol (Vitamin D), $\alpha$ Tocopherol (Vitamin E) and Vitamin K were assayed in High Performances Liquid Chromatography. Fish tissue $(30 \mathrm{~g})$ was grinded with anhydrous sodium sulfate. Then extracted its oil using 2:1 chloroform: methanol after adding BHA as antioxidants (Folch et al., 1957). The sample preparation and vitamin analysis was done as per Sankar et al. (2010). To about $2.0 \mathrm{~g}$ oil in a round bottom flask, added $25 \mathrm{ml}$ alcohol, and $1.5 \mathrm{ml}$ of $150 \% \mathrm{KOH}$. Reflux in water bath for $30 \mathrm{~min}$. Transfer the contents in to a $250 \mathrm{ml}$ separating funnel after cooling; wash the flask with $50 \mathrm{ml}$ petroleum ether and add to the separating funnel; shake the contents thoroughly and allowed to separate. Extract the aqueous layer twice more and pool the solvent layer. Wash the solvent layer with $20 \%$ of water $(\mathrm{v} / \mathrm{v})$ to make it alkali free. Concentrate nonsaponifiable matter in the ether extract fraction using a flash evaporator at $30-40^{\circ} \mathrm{C}$ to a definite volume. The non safonifiable matter is filtered through $0.45 \mu$ syringe filter and stored under refrigerator. Then the fat soluble vitamins were analyzed by injecting $20 \mu \mathrm{L}$ of sample in HPLC equipped with $\mathrm{C}_{18}$ Bondapack column. The mobile phase of HPLC consists of water (HPLC grade) solvent A and acetonitrile as solvent B with $1 \%$ TFA. A gradient system was used (solvent A/solvent B), starting from $50 / 50,80 / 20$ to $100 / 0$ at the rate of $1 \mathrm{~mL} / \mathrm{min}$ for $20 \mathrm{~min}$. The fat soluble vitamins were identified and quantified by comparing with the retention times and peak area of respective vitamins standards. The vitamin content in the sample is determined from the linear graph drawn for the standard (AOAC, 2005).

\section{Fatty acid analysis}

Pooled samples were extracted for fatty acid analysis following the method of Folch et al. (1957) using chloroform and methanol $(2: 1, \mathrm{v} / \mathrm{v})$ solvent system that contained $0.01 \%$ butylated hydroxyl anisole as an antioxidant. Fatty acid methyl esters (FAMEs) were prepared by the transmethylation with boron trifluoride $\left(\mathrm{BF}_{3}, \mathrm{Hi}\right.$ Media, Mumbai, India) in methanol from lipids fraction according to Metcalfe et al. (1966). The fatty acid methyl esters were quantified by injecting $1 \mu \mathrm{L}$ (50:1 split ratio) into a Gas Chromatograph (GC) (Perkin Elmer; CLARUS 480). The oven temperature was programmed from an initial temperature at $30^{\circ} \mathrm{C}$ rising to $140^{\circ} \mathrm{C}$ (hold time $4 \mathrm{~min}$.) and up to $200^{\circ} \mathrm{C}$. Nitrogen gas was used as a carrier gas. The injection port and the flame ionization detector were maintained at 260 and $300^{\circ} \mathrm{C}$. GC operating software "Total Chrom" was followed. Identification of individual FA was identified by comparison of retention times to those of standards (SUPELCO, 
Cat. No.47885-U) and quantified by comparing with respective areas. The data are presented as Mean \pm S.E. The data were analyzed using t-test as per Snedecor and Cochran (1968).

\section{RESULTS AND DISCUSSION}

The amino acid content of magur and singhi are presented in table 1 . The essential amino acid (EAA) content (g/100g protein) is $42.63 \pm 1.53$ and $42.21 \pm 0.37$ respectively in magur and singhi. The arginine content was significantly $(\mathrm{P}<0.05)$ higher in magur in comparison to singhi and on the contrary phenylalanine was significantly $(\mathrm{P}<0.05)$ higher in singhi. Other essential amino acids did not differ significantly between the species. However leucine, valine and threonine were higher in both magur and singhi among the EAA. The non-essential amino acid (NEAA) content is $54.58 \pm 0.61$ and $56.57 \pm 0.13$ in singhi and magur. Glutamic acid, glycine, alanine, aspartic acid are maximum in both singhi and magur among NEAA.

The present study for the amino acid content of magur and singhi shows that histidine, isoleucine, leucine, valine, phenylalanine and valine among the essential amino acid (EAA) and aspartate, glutamate, glycine, alanine and serine among the non essential amino acid (NEAA) are maximum in quantity. However, Iwasake and Harada (1985) reported that the main amino acids of fish are aspartate, glutamate and lysine. Over the last 20 years, increasing evidence suggests the importance of glutamine for the proper functioning of many organ systems (Christina et al., 1999). The most abundant free amino acid in the body, comprising nearly $60 \%$ of the intracellular amino acid in the skeletal muscle (Kenari et al., 2009). It serves as an important carrier for transporting the ammonia (nitrogen) from muscle to the splanchnic area and immune system (Deutz et al., 1992). Glutamine also acts as donor of nitrogen in the synthesis of purines and pyrimidines and helps in the proliferation of cells (Limin et al., 2006). Our study denotes that both magur and singhi contains glutamine as $14.61 \pm 0.05$ and $15.41 \pm 0.54$ (g/100g protein) respectively. Similar values of glutamic acid have also been reported earlier in mackerel (Hou et al., 2011) and food fishes of India (Mohanty et al., 2014). The present study shows the presence of a better amount of essential and non essential amino acids in both magur and singhi. It is observed that the EAA/NEAA ratio is 0.78 in magur and 0.75 in singhi. In this study there was no significant variation in amino acid content for both magur and singhi and hence it shows that both the fishes act as a great source of amino acid. 
Table 1. Amino acid content ( $\mathrm{g} / 100 \mathrm{~g}$ protein) of Two Indian Catfish

\begin{tabular}{l|l|l}
\hline Particulars & Magur & Singhi \\
\hline Arg & $4.39^{\mathrm{b}} \pm 0.86$ & $1.56^{\mathrm{a}} \pm 0.49$ \\
His & $4.12 \pm 0.18$ & $4.02 \pm 0.70$ \\
Ile & $4.81 \pm 0.28$ & $5.37 \pm 0.70$ \\
Leu & $8.35 \pm 0.07$ & $7.96 \pm 0.71$ \\
Lys & $4.23 \pm 0.79$ & $3.85 \pm 0.39$ \\
Met & $2.38 \pm 0.86$ & $1.41 \pm 0.25$ \\
Phe & $3.81^{\mathrm{a}} \pm 0.10$ & $6.08^{\mathrm{b}} \pm 0.07$ \\
Thr & $5.01 \pm 0.40$ & $5.81 \pm 0.20$ \\
Try & $1.17 \pm 0.05$ & $0.60 \pm 0.42$ \\
Val & $6.49 \pm 0.21$ & $5.72 \pm 0.87$ \\
$\sum$ EAA & $42.63 \pm 1.53$ & $42.21 \pm 0.37$ \\
Asp & $11.19 \pm 0.63$ & $12.34 \pm 0.64$ \\
Ser & $5.33 \pm 0.95$ & $5.94 \pm 0.38$ \\
Glu & $14.61 \pm 0.15$ & $15.41 \pm 0.54$ \\
Pro & $1.30 \pm 0.50$ & $0.74 \pm 0.04$ \\
Gly & $14.20 \pm 1.05$ & $14.70 \pm 0.20$ \\
Ala & $7.24 \pm 0.05$ & $6.34 \pm 0.61$ \\
Cys & $0.11 \pm 0.01$ & $0.12 \pm 0.01$ \\
Tyr & $0.68 \pm 0.17$ & $0.96 \pm 0.49$ \\
$\sum$ NEAA & $54.58 \pm 0.61$ & $56.57 \pm 0.13$ \\
EAA/NEAA & 0.78 & 0.75 \\
\hline
\end{tabular}

a,b Means with different superscripts in a row differ significantly $(\mathrm{P}<0.05)$

Table 2. Vitamin content (w/w basis) of Two Indian Catfish

\begin{tabular}{l|l|l}
\hline Particulars & Magur & Singhi \\
\hline A $\left(\mathrm{I} . \mathrm{U} 100 \mathrm{~g}^{-1}\right)$ & $6.03^{\mathrm{b}} \pm 0.01$ & $4.06^{\mathrm{a}} \pm 0.07$ \\
D $\left(\mathrm{I} . \mathrm{U} 100 \mathrm{~g}^{-1}\right)$ & $44.73^{\mathrm{b}} \pm 0.31$ & $26.23^{\mathrm{a}} \pm 1.01$ \\
E $\left(\mathrm{I} . \mathrm{U} 100 \mathrm{~g}^{-1}\right)$ & $0.15 \pm 0.04$ & $0.13 \pm 0.05$ \\
K $\left(\mu \mathrm{g} 100 \mathrm{~g}^{-1}\right)$ & $0.53^{\mathrm{a}} \pm 0.13$ & $3.80^{\mathrm{b}} \pm 0.71$ \\
\hline
\end{tabular}

${ }^{a, b}$ Means with different superscripts in a row differ significantly $(\mathrm{P}<0.05)$ 
The fat soluble vitamin content of magur and singhi are presented in table 2 . The vitamin A content (I.U./100g) is $6.03 \pm 0.01$ and $4.06 \pm 0.07$ respectively in magur and singhi. The vitamin $\mathrm{A}$ and $\mathrm{D}$ content are significantly $(\mathrm{P}<0.05)$ higher in magur when compared to singhi. The vitamin $\mathrm{K}$ content $\left(\mu \mathrm{g} 100 \mathrm{~g}^{-1}\right)$ is $0.53 \pm 0.13$ and $3.80 \pm 0.71$ respectively in magur and singhi. The vitamin $\mathrm{K}$ content is significantly $(\mathrm{P}<0.05)$ higher in singhi when compared to magur.

Fish is a good source of fat soluble vitamins like A, D, E and K (Paul et al., 2016). Although information related to fat soluble vitamin content in fish is limited. The vitamin content in fish muscle varies with species, age, season, sexual maturity and geographical areas. Vitamin A responsible for normal vision and bone growth is well known and its derivative retinoic acid regulates gene expression in the development of epithelial tissue (Roos et al., 2003). The vitamin D content is significantly $(\mathrm{P}<0.05)$ higher in magur compared to singhi. Vitamin $\mathrm{D}$ is a secosteroids responsible for enhancing intestinal absorption of calcium and phosphate. In humans, the most important compounds in this group are vitamin $\mathrm{D}_{3}$ (cholecalciferol) and vitamin $\mathrm{D}_{2}$ (ergocalciferol) (Hollick, 2006). Cholecalciferol and ergocalciferol can be ingested from the diet and from supplements (Hollick, 2006 and Norman, 2008). Vitamin D functions to activate the innate and dampen the adaptive immune systems (Hewison, 2011). As catfish contains a good amount of vitamin $\mathrm{D}$, hence it plays a major role for our immune system also prevent us from osteomalacia, caused by the deficiency of vitamin D. Vitamin E is an indispensable nutrient required to maintain flesh quality, immunity, normal resistance of red blood corpuscles to haemolysis, permeability of capillaries and heart muscles (Halver, 2002). Catfish contains vitamin $E$ and it ranges from 0.13 to 0.15 (I.U/100g). Vitamin $\mathrm{E}$ also functions as lipid soluble antioxidants and protects biological membranes, lipoproteins and lipids against oxidation (Hamre, 1998). Singhi contains higher amount of vitamin $\mathrm{K}$ as compared to magur. The human body needs vitamin $\mathrm{K}$ for post translational modifications of certain proteins required for blood coagulation and in metabolic pathways in bone and other tissue and they are 2-methyl-1, 4naphthoquinone 3-derivatives.

The fatty acid profile of magur and singhi are presented in table 3 . The saturated fatty acid (SFA) content is $36.11 \pm 1.94$ and $36.44 \pm 0.46$ (\% of total fatty acid) respectively in magur and singhi. Among the SFA, undecanoic acid, lauric acid, pentadecanoic acid, heptadecanoic acid and stearic acid are significantly $(\mathrm{P}<0.05)$ higher in magur when compare with singhi. The monounsaturated fatty acid (MUFA) content is $38.36 \pm 4.62$ and $49.69 \pm 7.87$ respectively in magur and singhi. The predominant MUFA is oleic acid and it is significantly $(\mathrm{P}<0.05)$ higher in singhi when compared to magur. Other MUFA present in the species were palmitoleic acid and pentadecenoic acid. Among the PUFA, $\alpha$-linolenic acid was significantly $(\mathrm{P}<0.05)$ higher in magur in comparison to singhi and on the contrary eicosatrienoic acid was significantly $(\mathrm{P}<0.05)$ higher in singhi compared to magur. 
Table 3. Fatty acid profile (\% of total fatty acid) of Two Indian Catfish

\begin{tabular}{l|l|l}
\hline Fatty acids & Magur & Singhi \\
\hline Butyric acid (C4:0) & $0.09 \pm 0.01$ & $0.25 \pm 0.11$ \\
Capric acid (C10:0) & $0.10 \pm 0.03$ & $0.16 \pm 0.09$ \\
Undecanoic acid (C11:0) & $0.75^{\mathrm{b}} \pm 0.14$ & $0.02^{\mathrm{a}} \pm 0.01$ \\
Lauric acid (C12:0) & $2.50^{\mathrm{b}} \pm 0.23$ & $0.86^{\mathrm{a}} \pm 0.23$ \\
Tridecanoic acid (C13:0) & $0.59 \pm 0.15$ & $\mathrm{ND}$ \\
Myristic acid (C14:0) & $\mathrm{ND}$ & $6.12 \pm 1.18$ \\
Pentadecanoic acid (C15:0) & $2.27^{\mathrm{b}} \pm 0.59$ & $0.03^{\mathrm{a}} \pm 0.01$ \\
Palmitic acid (C16:0) & $7.26 \pm 1.21^{\mathrm{a}}$ & $25.10^{\mathrm{b}} \pm 4.98$ \\
Heptadecanoic acid (C17:0) & $5.09^{\mathrm{b}} \pm 1.02$ & $0.23^{\mathrm{a}} \pm 0.12$ \\
Stearic acid (C18:0) & $8.54^{\mathrm{b}} \pm 0.45$ & $3.16^{\mathrm{a}} \pm 0.16$ \\
Arachidic acid (C20:0) & $0.37 \pm 0.005$ & $\mathrm{ND}$ \\
Heneicosanoic acid (C21:0) & $8.55 \pm 4.11$ & $\mathrm{ND}$ \\
Behenic acid (C22:0) & $\mathrm{ND}$ & $0.51 \pm 0.11$ \\
$\sum$ SFA & $36.11 \pm 1.04$ & $36.44 \pm 0.46$ \\
Myristoleic acid (C14:1) & $0.07 \pm 0.02$ & $0.06 \pm 0.02$ \\
Cis-10-Pentadecenoic acid (C15:1) & $2.28 \pm 0.71$ & $2.42 \pm 1.90$ \\
Palmitoleic acid (C16:1) & $6.49 \pm 1.14$ & $5.94 \pm 2.01$ \\
Heptadecenoic acid (C17:1) & $0.22 \pm 0.01$ & $0.14 \pm 0.07$ \\
Oleic acid (C18:1n9) & $28.96^{\mathrm{a}} \pm 2.78$ & $41.13^{\mathrm{b}} \pm 2.84$ \\
Eicosanoic acid (C20:1n9c) & $0.34 \pm 0.05$ & $\mathrm{ND}$ \\
$\sum$ MUFA & $38.36 \pm 4.62$ & $49.69 \pm 7.87$ \\
Linolelaidic acid (C18:2n6t) & $0.16 \pm 0.07$ & $0.11 \pm 0.09$ \\
Linoleic acid (C18:2n6c) & $13.76 \pm 2.56$ & $\mathrm{ND}$ \\
$\gamma$-Linolenic acid (C18:3n6) & $0.96 \pm 0.78$ & $0.06 \pm 0.01$ \\
$\alpha$-Linolenic acid (C18:3n3) & $2.43 \pm 0.02^{\mathrm{b}}$ & $0.23 \pm 0.01^{\mathrm{a}}$ \\
Eicosadienoic acid (C20:2n6) & $1.49 \pm 0.85$ & $1.08 \pm 0.56$ \\
Eicosatrienoic acid (C20:3n6) & $1.19^{\mathrm{a}} \pm 0.14$ & $5.80^{\mathrm{b}} \pm 0.17$ \\
Eicosatrienoic acid (C20:3n3) & $0.30 \pm 0.09$ & $0.80 \pm 0.19$ \\
Arachidonic acid (C20:4n6) & $\mathrm{ND}$ & $0.58 \pm 0.21$ \\
Eicosapentaenoic acid (C20:5n3) & $2.98 \pm 1.00$ & $3.60 \pm 1.11$ \\
Docosahexaenoic acid(C22:6n3) & $2.25 \pm 0.86$ & $1.60 \pm 1.09$ \\
$\sum$ PUFA & $25.52 \pm 1.40$ & $13.86 \pm 0.64$ \\
\hline
\end{tabular}




\begin{tabular}{l|l|l}
\hline Fatty acids & Magur & Singhi \\
\hline$\sum \omega 3$ & $7.96 \pm 0.58$ & $6.23 \pm 0.74$ \\
$\sum \omega 6$ & $17.56^{\mathrm{b}} \pm 2.57$ & $7.63^{\mathrm{a}} \pm 1.08$ \\
$\omega 3: \omega 6$ & $0.45: 1$ & $0.82: 1$ \\
\hline
\end{tabular}

${ }^{\mathrm{a}, \mathrm{b}}$ Means with different superscripts in a row differ significantly $(\mathrm{P}<0.05)$

Both the catfish posses two important PUFAs, viz., eicosapentanoic acid (EPA) and docosahexaenoic acid (DHA) and these range from $2.98-3.60(\%)$ as EPA and 1.60-2.25 (\%) as DHA. The PUFA content was 25.52 \pm 1.40 and 13.86 \pm 0.64 in magur and singhi respectively. The $\omega 6$ PUFA was significantly $(\mathrm{P}<0.05)$ higher in magur compared to singhi. The $\omega 3$ and $\omega 6$ ratio $(\omega 3: \omega 6)$ was $0.45: 1$ and $0.82: 1$ respectively in magur and singhi.

The fatty acid composition of aquatic animals are influenced by intrinsic variables, such as species, sex, age and size; as well as extrinsic factors, such as diet, salinity, temperature, geographical regions, and the general rearing conditions (Paul et al., 2015). Fatty acids in fishes are derived from two main sources, namely, biosynthesis and diet (Kamler et al., 2001). The chain length varies from $\mathrm{C}_{14}-\mathrm{C}_{24}$ of varying degree of unsaturation, from saturated to polyunsaturated (Swapna et al., 2010). Palmitic acid content among the SFA is maximum (25.10\%) in singhi which is in agreement with earlier report (Kaya et al., 2008). Among MUFA the oleic acid content was $28.96 \%$ in magur and it is similar to earlier reports (Swapna et al., 2010 and Jakhar et al., 2012). The palmitic acid was considered as a key to many metabolic processes in fish and other aquatic animals (Mohanty et al., 2016). The PUFA content of magur in the present experiment is reported to $25.52 \pm 1.40$ and it is in agreement with the study in other freshwater fish (Swapna et al., 2010, Kenari et al., 2009 and Jakhar et al., 2012). Fish oils are known to be rich source of essential PUFA of the omega-3 family, including both EPA and DHA (Kenari et al., 2009 and Paul et al., 2015).

\section{CONCLUSION}

The results indicated that Indian catfish is a good source of essential amino acid. Among fatty acid profile, palmitic and stearic acid are maximum among SFA and oleic acid and myristic acid are predominant among MUFA. Among PUFA the fish is enriched with linolenic acid, DHA and EPA. Vitamin A and D are also rich in good amount in both the catfish.

\section{ACKNOWLEDGEMENT}

This work was supported by the Ministry of Agriculture and Farmers Welfare, Government of India under ICAR Outreach Activity-3 on Nutrient Profiling and Evaluation of fish as a Dietary component. The authors wish to thank DDG (Fy, 
ICAR) for supporting the programme. Authors also greatly acknowledge the help of Director, ICAR-CIFA for providing necessary facility to conduct the work.

\section{REFERENCES}

Christina, J., Palmer, A. and Griffiths, R. D.1999. Randomized clinical outcome study of critically ill patients given glutamine supplemented internal nutrition. Nutrition, 15: $108-115$

Deutz, N. E. P., Reijven, P. L. M., Athanasas, G. and Soeters, P. B. 1992. Post operative changes in hepatic, intestinal, splenic and muscle fluxes of amino acids and ammonia in pigs. Clinical Science, 83: 607-614

Folch, J., Less, M. and Stanley, G. H. S. 1957. A simple method for the isolation and purification of total lipids from animal tissues. Journal of Biochemistry, 226:497-509

Giri, S. S., Paul, B. N., Sahoo, S. K., Rangacharyulu, P. V., Rath, S. C. and Mohanty, S. N. 2010. Fish oils and cardio vascular health. Fishing Chimes, 30(2): 37-39

Giri, S. S., Sahoo, S. K. and Paul, B. N. 2011. Initiatives to conserve long chain polyunsaturated fatty acids (LC-PUFA) in human being through Aquaculture.p.28-31. In Proc. National Conference of Indian Academy of Veterinary Nutrition and Animal Welfare $1^{\text {st }}$, Durg, India, 24-25 ${ }^{\text {th }}$ Sept. 2011

Hamre, K., Berge, R. K. and Lie, O. 1998. Turnover of $\alpha-, \gamma-$, and $\delta$-tocopherol and distribution in subcellular and lipoprotein fractions indicate presence of a hepatic tocopherol binding protein in Atlantic salmon (Salmo salar L.). Fish Physiology and Biochemistry, 18: 71-83

Holick, M. F. 2006. High prevalence of vitamin D inadequacy and implications for health. Mayo Clinical Proceedings, 81 (3): 353-73

Hou, H., Li, B. and Zhao, X. Enzymatic hydrolysis of defatted mackerel protein with low bitter taste. 2011. Journal of Ocean University China (Oceanic and Coastal Sea Research), 10: 85-92

Ishida, Y., Fujita, T. and Asai, K. 1981. New detection and separation method for amino acids by high-performance liquid chromatography. Journal of Chromatography, 204: 143148

Iwasaki, M. and Harada, R. 1985. Proximate and amino acid composition of the roe and muscle of selected marine species. Journal of Food Science, 50: 1585-1587

Jakhar, J. K., Pal, A. K., Reddy, A. D., Sahu, N. P., Venkateshwarlu, G. and Vardia, H. K. 2012. Fatty acid composition of some selected Indian fishes. African Journal of Basic \& Applied Science, 4(5): 155-160

Kamler, E. B., Krasicka, S. and Rakusa-Suszczewski. 2001. Comparison of lipid content and fatty acid composition in muscle and liver of two Notothenioid fishes from Admiralty Bay (Antartica): An eco-physiological perspective. Polar Biology, 24: 735-743

Kaya, Y., Turan, H. and Erdem, M. E. 2008. Fatty acid and Amino acid composition of raw and hot smoked sturgeon (Huso huso, L. 1758). International Journal of Food Science and Nutrition, 59(7-8):635-642 
Kenari, A. A., Regenstein, J. M., Rezai, M., Tahergorabi, R., Nazari, R. M., Mogaddasi, M. and Kaboli, S. A. 2009. Amino acid and fatty acid composition of cultured Beluga (Huso huso) of different ages. Journal of Aquatic Food Product and Technology, 18:245-265

Kumar, D. 1992. Fish culture in Un-drainable ponds. A manual for extension FAO Fisheries Technical paper, No. 235:239

Limin, L., Feng, X. and Jing, H. 2006. Amino acid composition difference and nutritive evaluation of the muscle of five species of marine fish, Pseudosciaena crocea (large yellow croaker), Lateolabrax japonicus (common sea perch), Pagrosomus major (red seabream), Seriola dumerili (Dumeril's amberjack) and Hapalogenys nitens (black grunt) from Xiamen Bay of China. Aquaculture Nutrition, 12: 53-59

Metcalfe, L. D., Schmitz, A. A. and Petha, J. R. 1996. Rapid preparation of fatty acid esters from lipids for gas chromatographic analysis. Analytical Chemistry, 38: 514-515

Mohanty, B. P., Mahanty, A., Ganguly, S., Sankar, T. V., Chakraborty, K., Anandan, R., Paul, B. N., Sarma, D., Mathew, S., Asha, K. K., Behera, B. K., Afftabuddin, M., Debnath, D., Vijaygopal, P., Sridhar, N., Akhtar, M. S., Sahi, N., Mitra, T., Banerjee, S.,Paria, P., Das, D., Das, P., Vijayan, K. K., Lamanan, P. T. and Sharma, A. P. 2014. Amino Acid composition of 27 Food fishes and their importance in Clinical Nutrition. Journal of Amino Acid, 1:1-7. Doi.org/10.1155/2014/269797

Mohanty, B. P., Ganguly, S., Mahanty, A., Sankar, T. V., Anandan, R. Chakraborty, K., Paul, B. N., Sarma, D., Dayal, J. S., Venkateshwarlu, G., Mathew, S., Asha, K. K., Karunakaran, D., Mitra, T., Banerjee, S., Chanda, S., Shahi, N., Das, P., Das P., Akhtar, M. S., Vijayagopal, P. and Sridhar, N. 2016. DHA, EPA content and Fatty acid Profile of 39 Food Fishes from India. Biomed Research International, Doi.10.1155/2016/4027437

Norman, A. W. 2008. From vitamin D to hormone D: fundamentals of the vitamin D endocrine system essential for good health. American Journal Clinical Nutrition, 88 (2):491S-499S

Paul, B. N., Sarkar, S., Giri, S. S. and Mohanty, S. N. 2005. Vtamin E requirement of Catla catla Fry. Indian Journal of Animal Nutrition, 22(4): 237-240

Paul, B. N., Chanda, S., Sridhar, N., Saha, G. S. and Giri, S. S. 2016. Proximate, mineral and vitamin contents of Indian Major Carp. Indian Journal of Animal Nutrition, 33(1): 102107. Doi. 10.5958/2231-6744.2016.00018.9

Paul, B. N., Chanda, S., Sridhar, N., Saha, G. S. and Giri, S. S. 2015 Fatty acid profile of Indian Major Carp. Indian Journal of Animal Nutrition, 32(2): 221-226

Roos, N., Islam, M. M. and Thilsted, S. H. 2003. Small fish is an important dietary source of vitamin A and calcium in Bangladesh. Journal of Nutrition, 133:4021S-4026S

Sanchez-Alonso, I., Jimenez-Escrig, A., Saura-Calixto, F. and Borderias, A. J. 2007. Effect of grape antioxidant dietary fiber on the prevention of lipid oxidation in minced fish: Evaluation by different methodologies. Food Chemistry, 101: 372-378.

Sankar, T. V., Susheela, M., Anandan, R., Asha, K. K. and Mohanty, B. P. 2010. Central Institute of Fisheries Technology, Indian Council of Agricultural Research. pp. 61 
Sau, S. K., Paul, B. N., Mohanta, K. N. and Mohanty, S. N. 2004. Dietary vitamin E requirement, fish performance and carcass composition of rohu (Labeo rohita) fry. Aquaculture, 240: 359-368.

Snedecor, G. W. and Cochran, W. G. 1968. Statistical Methods. $6^{\text {th }}$ edition. Oxford and IBH Publishing Company, Calcutta, India

Swapna, H. C., Kumar, R. A., Bhaskar, N. and Sachindra, N. M. 2010. Lipid classes and fatty acid profile of selected Indian freshwater fishes. Journal of Food Science and Technology, 47(4): 394-400 